\title{
Corrosion resistance of non-stoichiometric gadolinium zirconate fabricated by laser-enhanced chemical vapor deposition
}

\author{
Chengguan ZHANG, Yun FAN, Juanli ZHAO, Guang YANG, Hongfei CHEN, \\ Liangmiao ZHANG, Yanfeng GAO, Bin LIU*
}

School of Materials Science and Engineering, Shanghai University, Shanghai 200444, China

Received: September 11, 2020; Revised: December 24, 2020; Accepted: December 24, 2020

(C) The Author(s) 2020.

\begin{abstract}
Gadolinium zirconate (GZ) is a promising candidate for next-generation thermal barrier coating (TBC) materials. Its corrosion resistance against calcium-magnesium-alumino-silicate (CMAS) needs to be further increased for enhancing its in-service life. As the Gd element plays an important role in the CMAS resistance, three GZ coatings (GZ-0.75, GZ-1.0, and GZ-1.2) with different $\mathrm{Gd} / \mathrm{Zr}$ atomic ratios are designed and deposited by laser enhanced chemical vapor deposition (LCVD) in this work. It is found that the generated Gd-apatite in GZ-1.2 would block micro-cracks inside the column structure and the inter-columnar gap more efficiently. Thus, the CMAS penetration rate $(5.2 \mu \mathrm{m} / \mathrm{h})$ of GZ-1.2 decreases over $27 \%$ comparing with GZ-1.0 and GZ-0.75, which is even lower than the $\mathrm{Gd}_{2} \mathrm{Zr}_{2} \mathrm{O}_{7}$ coatings fabricated by electron-beam physical vapor depositions (EB-PVDs). This work provides a feasible way to adjust the coating's corrosion resistance and may guide the development of future coating for long in-service life.
\end{abstract}

Keywords: thermal barrier coating (TBC); gadolinium zirconate (GZ); nonstoichiometry; corrosion resistance

\section{Introduction}

Thermal barrier coatings (TBCs) are widely used in protecting Ni-based super-alloys serviced in the hot sections of gas turbine engines. The application of TBCs makes metallic components maintain their mechanical properties at high temperatures $[1,2]$. Owing to its high servicing temperatures and required performance, the appropriate TBC materials should have a series of excellent properties, such as low thermal conductivity, no phase transition, high melting point, and good corrosion resistance. The current commercial TBC material is $7-8 \mathrm{wt} \% \mathrm{Y}_{2} \mathrm{O}_{3}$ partially stabilized $\mathrm{ZrO}_{2}$

* Corresponding author.

E-mail: binliu@shu.edu.cn
(YSZ), which has good compromise among the selection requirements $[3,4]$. However, YSZ is vulnerable to molten airborne dust (main components: calciummagnesium-alumino-silicate, CMAS) damage at high operating temperatures [1,5-9]. This disadvantage decreases the service-life and limits the long-term application of YSZ at enhanced temperatures. Thus, many efforts are taken to further increase the coatings' CMAS resistance.

Gadolinium zirconate (GZ) is a promising candidate of TBCs for the next-generation turbine engines [10-13]. The crystal structure of GZ can be described as a $\mathrm{Zr}_{4} \mathrm{O}_{12}$ framework with an imbricated $\mathrm{Gd}_{4} \mathrm{O}_{2}$ polyhedron inside [14-16]. Here, the $\mathrm{Zr}_{4} \mathrm{O}_{12}$ framework provides high-temperature structural stability, and the $\mathrm{Gd}_{4} \mathrm{O}_{2}$ polyhedron can scatter phonons and provide low thermal 
conductivity $[17,18]$. As a result, GZ has a high melting point $\left(2600{ }^{\circ} \mathrm{C}\right)$, a high structural stability up to $1600{ }^{\circ} \mathrm{C}$, and a lower thermal conductivity $(1.6 \mathrm{~W} /(\mathrm{m} \cdot \mathrm{K}))$ compared to YSZ $[2,19,20]$. Moreover, GZs exhibit good resistance against CMAS attack. Krämar et al. [21] pointed out that the apatite-type solid solution, which is generated during the corrosion process, has a key effect on corrosion resistance. Gd-apatite would clog the coating's porous structure so as to restrict the subsequent CMAS penetration [21,22]. Participating in the formation of the apatite, it is clear that the Gd content would influence the generation of apatite-type solid solutions. Meanwhile, the stable pyrochlore structure has a specific range (from 1.46 to 1.78) of $r_{\mathrm{A}} / r_{\mathrm{B}}\left(r_{\mathrm{A}}\right.$ and $r_{\mathrm{B}}$ represent the A- and B-site cations' radii of $\mathrm{A}_{2} \mathrm{~B}_{2} \mathrm{O}_{7}$, respectively) according to the theoretical study of $\mathrm{A}_{2} \mathrm{~B}_{2} \mathrm{O}_{7}$ compositions and the $\mathrm{RE}_{2} \mathrm{O}_{3}-\mathrm{ZrO}_{2}$ phase diagram [18,23-25]. Therefore, the Gd content of GZ is predicted adjustable, which is also considered as a feasible way to further increase the anti-CMAS ability.

However, the dissociation pressure and the vaporization rate of lanthanide oxides are higher than that of zirconia (at least an order of magnitude higher) [26,27]. As a result, a severe loss of Gd element would happen during commercial coating preparation methods, including the electron-beam physical vapor deposition (EB-PVD) and the atmospheric plasma spray (APS). Therefore, both of them can tailor the Gd content only in a small range. For example, Mauer et al. [28,29] reported the $\mathrm{Gd} / \mathrm{Zr}$ molar ratio of sprayed coatings ranged from 0.88 to 1.08 by adjusting the input power of the plasma jet during the APS process. Schmitt et al. [30] fabricated non-stoichiometric GZ coatings by rotating the substrate mandrel through the vapor cloud of GZ. The deposited coatings were $\mathrm{Gd}$ deficient with $\mathrm{Gd} / \mathrm{Zr}$ atomic ratios being $0.18,0.46,0.72$, and 1.00 .

Recently, laser enhanced chemical vapor deposition (LCVD) has been applied to fabricate TBCs [31,32]. Yang et al. [33] proved that LCVD method is a laboratory method to prepare GZ coatings with a wide $\mathrm{Gd} / \mathrm{Zr}$ ratio range, a high deposition rate (up to $307 \mu \mathrm{m} / \mathrm{h}$ ), and a unique columnar-like micro-structure. However, the influence of non-stoichiometric Gd content on the coating's CMAS resistance is still unknown. In this study, three GZ coatings with different $\mathrm{Gd} / \mathrm{Zr}$ ratios (i.e., GZ-0.75, GZ-1.0, and GZ-1.2) are fabricated and their corrosion resistance is investigated. The GZ with higher $\mathrm{Gd}$ content promotes the generation of Gd-apatite, blocking the inter-columnar gap and the micro-cracks inside the column efficiently. As a result, the penetration rate of GZ-1.2 decreases to $5.2 \mu \mathrm{m} / \mathrm{h}$, being lower than that of EB-PVD fabricated $\mathrm{Gd}_{2} \mathrm{Zr}_{2} \mathrm{O}_{7}$ coatings $(10-20 \mu \mathrm{m} / \mathrm{h})$ [34]. This work provides a feasible way to adjust the corrosion resistance of GZ against CMAS and may guide the design of future-coating with the enhanced corrosion resistance.

\section{Experimental}

\section{1 Fabrication of coatings}

The LCVD equipment consists of a cold-wall type chemical vapour deposition (CVD) and a compactevolution diode laser system (DILAS Inc., Mainz, Germany). The commercial metallo-organic compounds, Gd(TMHD) $)_{3}$ (Tris(2,2',6,6'-tetramethyl-3,5-heptanedionato) gadolinium(III), Strem chemicals, Inc., USA) and $\mathrm{Zr}(\mathrm{TMHD})_{4}$ (Zirconium tetrakis(2,2',6,6'-tetramethyl3,5-heptanedionate), Strem chemicals, Inc., USA), were used as raw materials. $\mathrm{Gd} / \mathrm{Zr}$ ratios of deposited coatings are controlled by the dosages of $\operatorname{Gd}(\mathrm{TMHD})_{3}$ and $\mathrm{Zr}(\mathrm{TMHD})_{4}$. Based on the formation region of high-quality GZ coatings, the applied $\operatorname{Gd}(\mathrm{TMHD})_{3} / \mathrm{Zr}(\mathrm{TMHD})_{4}$ molar ratios of 0.75 (GZ-0.75), 1.0 (GZ-1.0), and 1.2 (GZ-1.2) were chosen. For more details, please refer to our previous work [33]. During the deposition process, gaseous $\mathrm{Gd}(\mathrm{TMHD})_{3}$ and $\mathrm{Zr}(\mathrm{TMHD})_{4}$ were carried by argon gas and transported to the surface of the $\mathrm{Al}_{2} \mathrm{O}_{3}$ substrate (size: $20 \mathrm{~mm} \times 25 \mathrm{~mm} \times 0.7 \mathrm{~mm}$ ). The reaction between precursors was activated by a laser in the CVD chamber with an oxidizing environment (the partial pressure of oxygen was $900 \mathrm{~Pa}$ ) [35]. The output power of the diode laser was fixed at $400 \mathrm{~W}$ (continuous mode, wave length $\lambda=976 \pm 10 \mathrm{~nm}$ ). Furthermore, the temperature was maintained at $900{ }^{\circ} \mathrm{C}$ for the substrate and $350{ }^{\circ} \mathrm{C}$ for the transportation tube of the gaseous precursors. The deposition duration time is around 250-300 s and other details of LCVD parameters are listed in Table 1.

\section{2 Corrosion test and characterization}

To make the corrosion results in this study comparable with previous literature, the amorphous CMAS sample with a composition of $\mathrm{CaO}$ (33 mol\%)-MgO (9 mol\%)$\mathrm{Al}_{2} \mathrm{O}_{3}$ (13 $\left.\mathrm{mol} \%\right)-\mathrm{SiO}_{2}$ (45 mol\%) (the calculated basicity index is 1.09) [6] was adopted in this study. The CMAS glass was prepared by pure $\mathrm{CaO}, \mathrm{MgO}$, 
Table 1 Parameters for LCVD deposition

\begin{tabular}{lc}
\hline LCVD parameter (temperature setting/gas flow rate) & Values \\
\hline Substrate platform $\left({ }^{\circ} \mathrm{C}\right)$ & 900 \\
Vapor transportation tube $\left({ }^{\circ} \mathrm{C}\right)$ & 350 \\
Precursor evaporator $\left(\mathrm{Gd}(\mathrm{TMHD})_{3}\right)\left({ }^{\circ} \mathrm{C}\right)$ & $267 / 272 / 272$ \\
Precursor evaporator $\left(\mathrm{Zr}(\mathrm{TMHD})_{4}\right)\left({ }^{\circ} \mathrm{C}\right)$ & $362 / 366 / 378$ \\
\hline Carrier gas, argon $(\mathrm{mL} / \mathrm{min})$ & 20 \\
Carrier gas, $\operatorname{argon}(\mathrm{mL} / \mathrm{min})$ & 40 \\
Oxygen $(\mathrm{mL} / \mathrm{min})$ & 190 \\
Atmospheric pressure in chamber $(\mathrm{Pa})$ & 900 \\
Laser output power $(\mathrm{W})$ & 400 \\
Distance from nozzle to substrate $(\mathrm{mm})$ & 28 \\
\hline
\end{tabular}

$\mathrm{Al}_{2} \mathrm{O}_{3}$, and $\mathrm{SiO}_{2}$ powders in $99.9 \%$ purity. After fully grinding, the mixture of $\mathrm{CaO}, \mathrm{MgO}, \mathrm{Al}_{2} \mathrm{O}_{3}$, and $\mathrm{SiO}_{2}$ was heat-treated at $1250{ }^{\circ} \mathrm{C}$ for $4 \mathrm{~h}$. Then, amorphous CMAS samples with a density of $8 \mathrm{mg} / \mathrm{cm}^{2}$ were added to the coating surface. At last, the as-prepared specimens were heated at $1250{ }^{\circ} \mathrm{C}$ for 10,30 , and $60 \mathrm{~min}$, respectively.

The Vickers hardness of all deposited coatings was measured using a micro indentation tester (HXD1000TMC/LCD, China). The applied load is $0.3 \mathrm{~N}$ and the holding time is $10 \mathrm{~s}$. The coating's cross-sectional morphologies and element distribution were observed by the scanning electron microscope (SEM, HITACHI FlexSEM-1000, Japan) and the energy dispersion spectroscope (EDS, FEI F50, USA). The atomic ratio and phase composition of the as-sprayed coatings were determined by the inductively coupled plasma mass spectrometry (ICP-MS, Perkin Elmer Optima 8300DV, USA), the X-ray diffraction (XRD, Rigaku Industrial Corporation, Japan), and the Raman spectroscope (Gloucestershire, UK), respectively.

\section{Results and discussion}

\section{1 Morphologies and compositions of LCVD coatings}

Surface and cross-sectional morphologies (backscattering images) of three as-deposited coatings are shown in Fig. 1. The dark area at the bottom of the coating in all the cross-sectional microstructures is the $\mathrm{Al}_{2} \mathrm{O}_{3}$ substrate, and the LCVD coating has a strong bonding to the $\mathrm{Al}_{2} \mathrm{O}_{3}$ substrate. All coatings exhibit similar microstructures that are a cauliflower-like surface (Fig. 1(a)) and a columnar cross-section (Figs. 1(b) and 1(c)). Each columnar crystal has dendritic micro-cracks inside.
EDS was used to measure atomic ratios of three as-deposited coatings in different positions (Figs. 1(c)-1(e)). $\mathrm{The} \mathrm{Gd} / \mathrm{Zr}$ ratio varies slightly with depth, and the mean compositions of as-deposited coatings are 0.73 , 1.03 , and 1.17 , respectively. Moreover, the average reduction of the $\mathrm{Gd} / \mathrm{Zr}$ ratio in as-deposited coatings
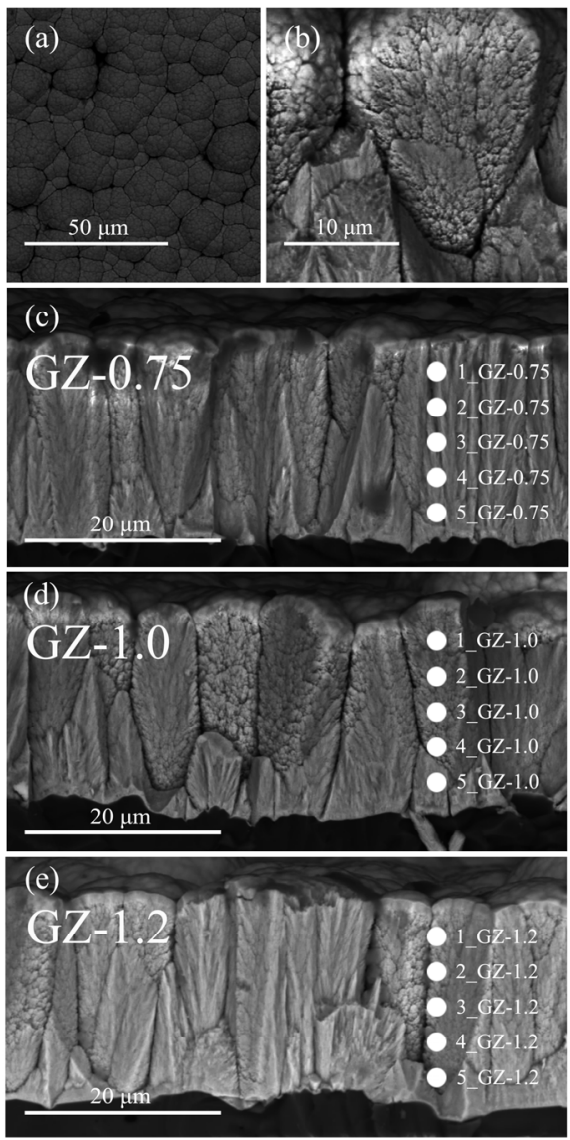

Fig. 1 (a) Surface, (b) local images of columnar, and (c-e) overall cross-section morphologies (backscattered electron images) of GZ coatings prepared by LCVD. Here, solid circles in (c-e) are positions for EDS measurement.

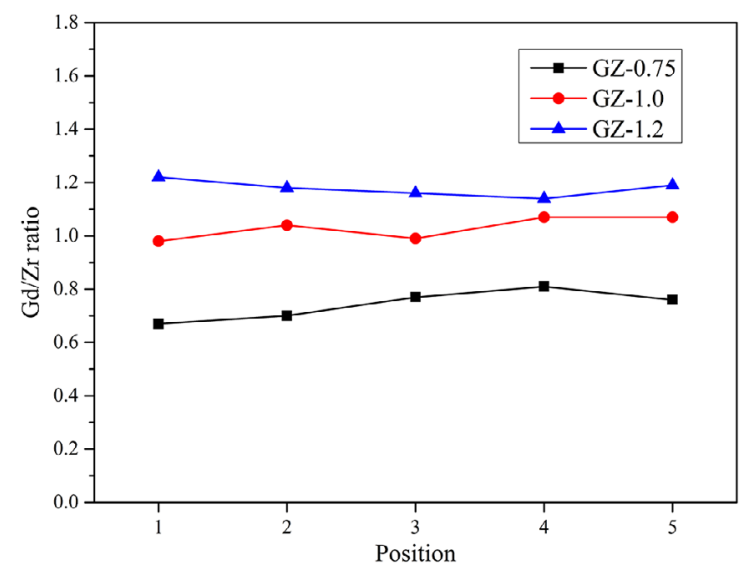

Fig. 2 EDS measured $\mathrm{Gd} / \mathrm{Zr}$ atomic ratios for all three GZ coatings in different positions of Figs. 1(c)-1(e). 
is 0.02 for GZ-0.75, -0.03 for GZ-1.0, and 0.03 for GZ-1.2, respectively, which is close to the $\mathrm{Gd} / \mathrm{Zr}$ ratio of the precursors. These results show the realization of non-stoichiometric GZ coatings with a wide $\mathrm{Gd} / \mathrm{Zr}$ ratio range.

The Vickers hardness values for all three coatings are $8.99 \mathrm{GPa}$ for GZ-0.75, 7.28 GPa for GZ-1.0, and 6.01 GPa for GZ-1.2, respectively (Fig. 3), being higher than or close to the hardness ( 6.5) of YSZ [36]. The results show that the coating's micro-hardness decreases with the increment of Gd content, which is consistent with other non-stoichiometric rare-earth zirconates in Refs. [36-38]. As the strong $\mathrm{Zr}-\mathrm{O}$ bonds of the corner-shared $\mathrm{ZrO}_{(1) 6}$ octahedra network contribute to the structural strength of the pyrochlore phase, the increment of $\mathrm{ZrO}_{2}$ content would increase the coating's hardness $[30,38]$.

\section{2 Phases of as-sprayed coatings}

The XRD patterns of all three GZ coatings are consistent with the $\mathrm{Gd}_{2} \mathrm{Zr}_{2} \mathrm{O}_{7}$ (\#75-8269, pyrochlore) PDF card (Fig. 4). Here, no impurity peak appears. Besides, all XRD peaks shift to the left side with the increasing of the Gd content. The anti-site position occupation will happen in non-stoichiometric GZs (the Gd excess case or the $\mathrm{Zr}$ excess case), which is demonstrated in Ref. [39]. As a result, the lattice constant increases along with the substitution of $\mathrm{Gd}^{3+}$ on $\mathrm{Zr}^{4+}$ in the Gd excess GZ. On the contrary, the decrement of the lattice constant happens when $\mathrm{Zr}^{4+}$ elements substitute for $\mathrm{Gd}^{3+}$ in the $\mathrm{Zr}$ excess cases. The above phenomenon can be verified by the composition-dependent lattice parameter (Fig. 5) and the change of main XRD peaks with different $\mathrm{Gd} / \mathrm{Zr}$ ratios (the inset in Fig. 4).

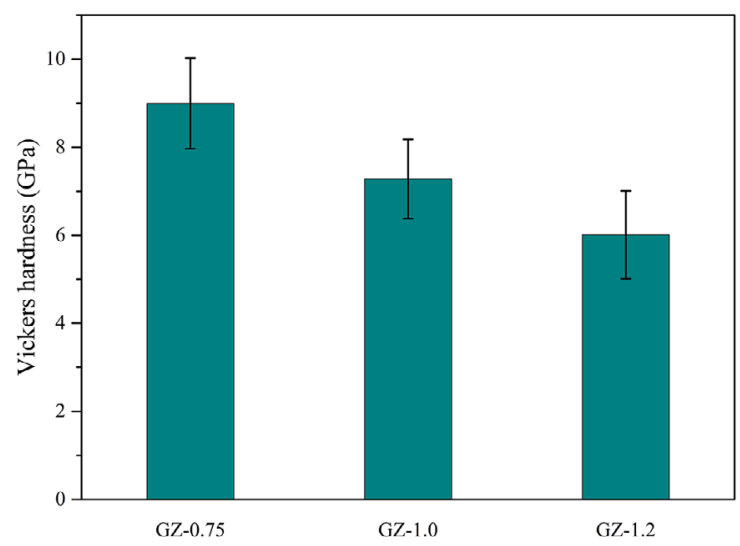

Fig. 3 Vickers hardness values measured on the surface of all three GZ coatings.

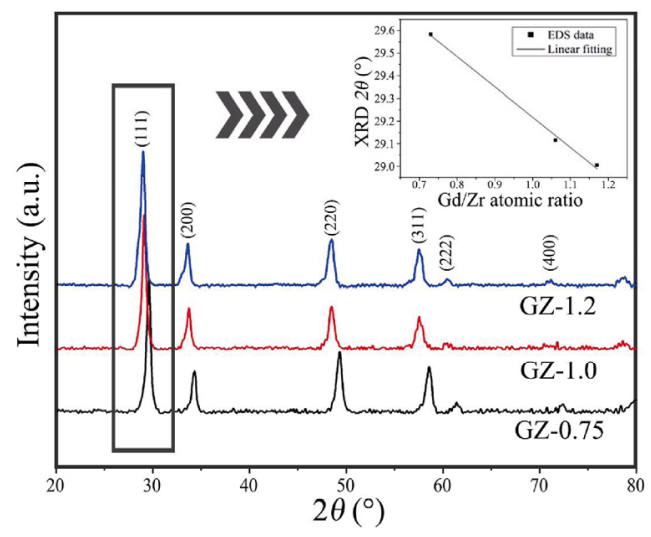

Fig. 4 XRD patterns of non-stoichiometric GZ coatings fabricated by LCVD.

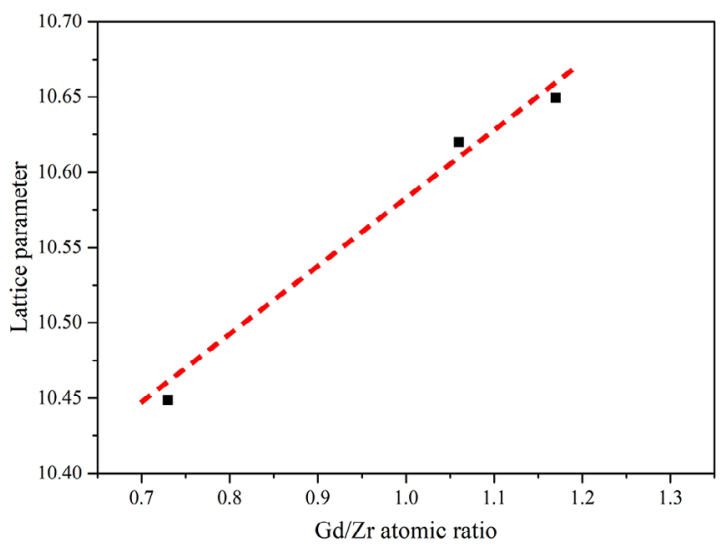

Fig. 5 Relationship between the lattice parameter of GZ and the $\mathrm{Gd} / \mathrm{Zr}$ ratio.

It is known that the stable pyrochlore structure has a specific range of $r_{\mathrm{A}} / r_{\mathrm{B}}$ from 1.46 to 1.78 . So, the substitution of $\mathrm{Gd}^{3+}$ and/or $\mathrm{Zr}^{4+}$ changes such ratio and will further change the phase composition of as-sprayed coatings [39]. However, the pyrochlore phase and the defect fluorite phase have almost the same XRD peaks except for the superstructure peaks at $\sim 36.3^{\circ}$ and $\sim 43.6^{\circ}$. Namely, the XRD pattern mainly shows the characteristic of the defect fluorite structure, but it is insufficient to indicate the existence and/or absence of the pyrochlore phase. Raman spectra can discern the phase composition by measuring the cation-anion bonds' arrangement inside the coatings. The Raman activity peaks are the result of the oxygen-related vibrations, which originate from the octahedral $\mathrm{ZrO}_{(1) 6}$ and the $\mathrm{Gd}_{4} \mathrm{O}_{(2) 2}$ networks. The Raman active vibrations in the pyrochlore phase are described as follows $[14,25,40]$ :

$$
\begin{gathered}
\mathrm{O}_{(2)}=\mathrm{T}_{2 \mathrm{~g}} \\
6 \mathrm{O}_{(1)}=\mathrm{A}_{1 \mathrm{~g}}+\mathrm{E}_{\mathrm{g}}+3 \mathrm{~T}_{2 \mathrm{~g}}
\end{gathered}
$$


Because the random arrangements of cations and anions in the fluorite phase lead to the homogenous distribution of chemical bonds, the translational symmetry would lose in such a situation. Thus, the Raman active vibration in the fluorite phase is described as follows:

$$
\Gamma_{(\mathrm{R}) \text { fluorite }}=\mathrm{T}_{2 \mathrm{~g}}
$$

where $A_{1 g}, E_{g}$, and one of the $T_{2 g}$ modes belong to the vibrations of $\mathrm{Zr}-\mathrm{O}_{(1) 6}$ octahedra; other three $\mathrm{T}_{2 \mathrm{~g}}$ modes belong to the anion-cation bonds like $\mathrm{Zr}-\mathrm{O}_{(1)}, \mathrm{Gd}-\mathrm{O}_{(1)}$, and $\mathrm{Gd}-\mathrm{O}_{(2)}$. The Raman spectra of the as-deposited GZ coatings are plotted in Fig. 6. In the spectral profile of GZ-1.0, 309, 400, and $\sim 580 \mathrm{~cm}^{-1}$, peaks corresponding to the pyrochlore phase can be identified. Along with the increment/decrement of the Gd content, the predominance of the fluorite phase starts to appear owing to the element substitution. In the GZ-1.2 case, the peak at $309 \mathrm{~cm}^{-1}$ has a hypsochromic shift with a bulge at $340 \mathrm{~cm}^{-1}$. In the GZ-0.75 case, the boundary between 309 and $400 \mathrm{~cm}^{-1}$ begins to blur. Moreover, the bulge at around $579 \mathrm{~cm}^{-1}$ corresponds to the pyrochlore phase that still exists in both GZ-0.75 and GZ-1.2 profiles. Therefore, the GZ-1.0 coating can be considered as a pyrochlore phase, and both GZ-0.75 and GZ-1.2 are the mixed-phase of pyrochlore and defect-fluorite.

\section{3 CMAS resistance}

Figure 7(a) shows the cross-sectional morphology (backscattered electron image) of the GZ-1.0 coating after exposure to molten CMAS for $60 \mathrm{~min}$. On top of the coating, the original columnar structure is totally obliterated, which illustrates a reaction between molten CMAS and GZ. Here, a reaction layer that contains a large number of crystal particles is located beneath the CMAS residue (Figs. 7(b)-7(d)). Based on the XRD

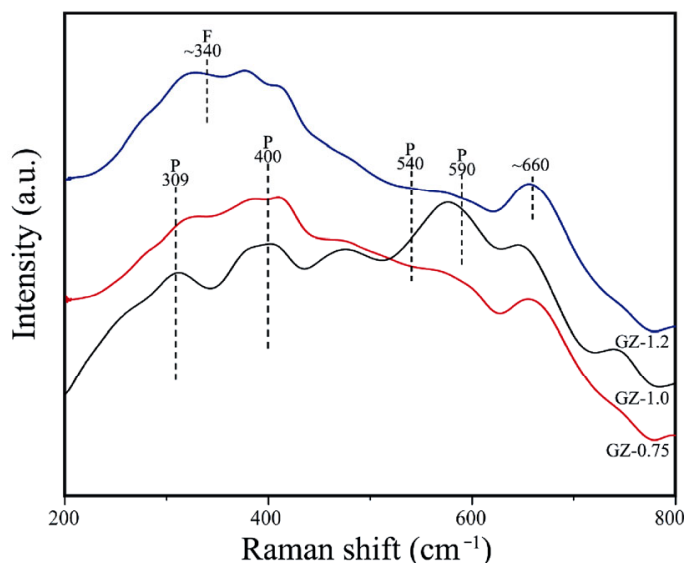

Fig. 6 Raman spectra of three GZ coatings fabricated by LCVD. Here, $\mathrm{P}$ and $\mathrm{F}$ are corresponding to the pyrochlore and fluorite phase, respectively.

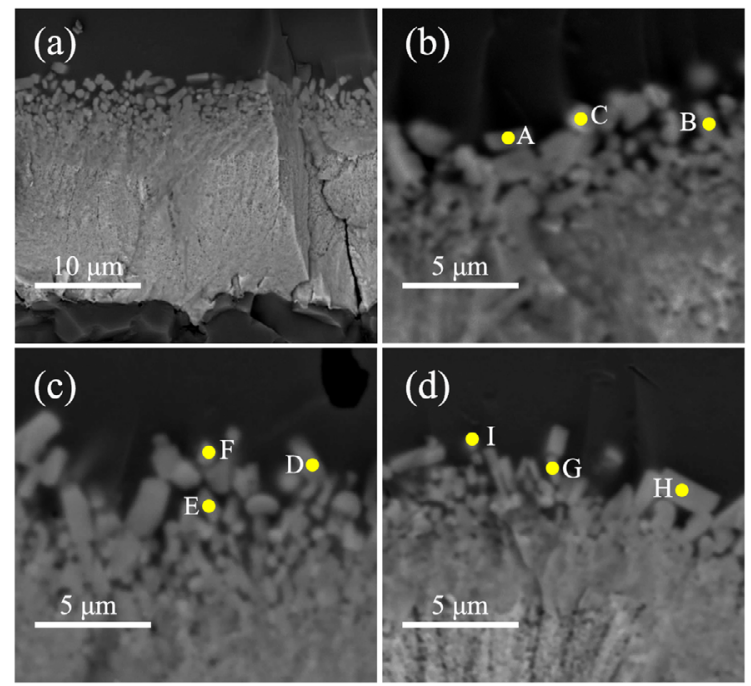

Fig. 7 Cross-sectional morphologies of (a) the corroded GZ-1.0, the reaction region of (b) GZ-0.75, (c) GZ-1.0, and (d) GZ-1.2 after exposure to molten CMAS for $60 \mathrm{~min}$. Here, points A to I are the positions for the EDS measurement.

analysis (Fig. 8), the particles in the reaction layer can be identified as globular zirconia (PDF \#89-9066) and stick-like Gd-apatite (PDF \#28-0212). Additionally, as the formation of $\mathrm{Gd}$-apatite depleted $\mathrm{Ca}$ and $\mathrm{Si}$, the supersaturation of $\mathrm{Al}$ oxides in the residual CMAS lead to the precipitation of anorthite. The above results are in agreement with Refs. [21,41]. Figure 9 shows that the element contents of $\mathrm{Ca}, \mathrm{Mg}, \mathrm{Al}$, and $\mathrm{Si}$ decrease gradually along with the penetration depth. Such element distributions have a clear boundary between the reaction layer and the GZ coating. This result suggests that the existence of the apatite-type solid solution (Fig. 7) restricts the penetration of molten CMAS.

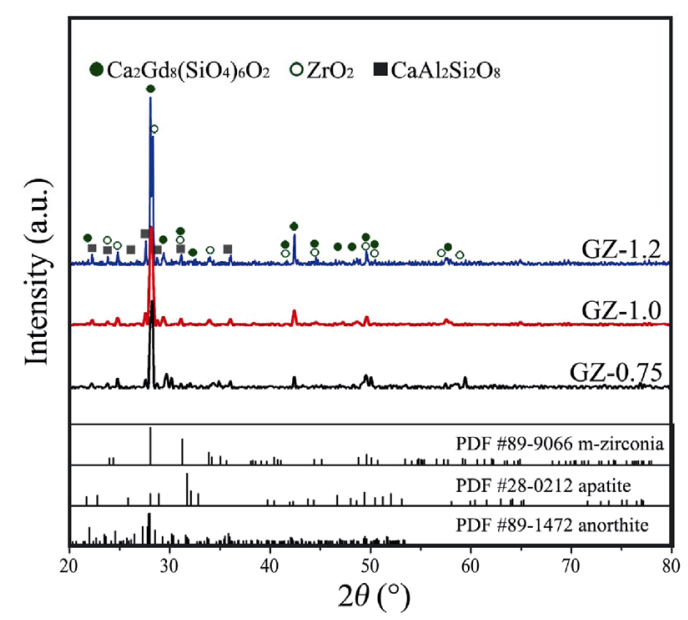

Fig. 8 XRD patterns of the deposited coating after exposure to CMAS melt for $60 \mathrm{~min}$. 
(a)

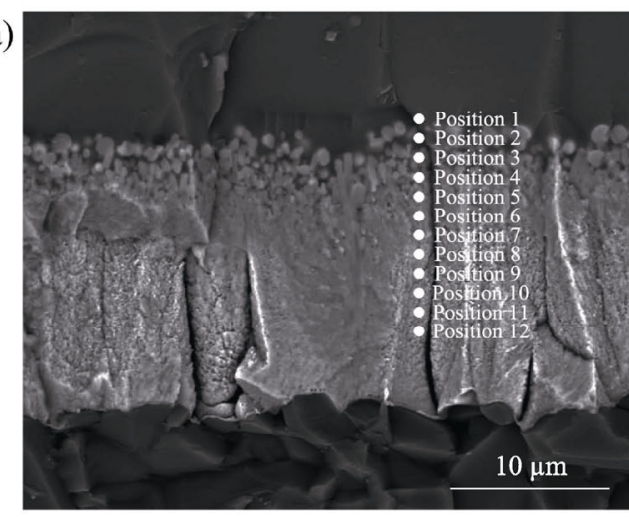

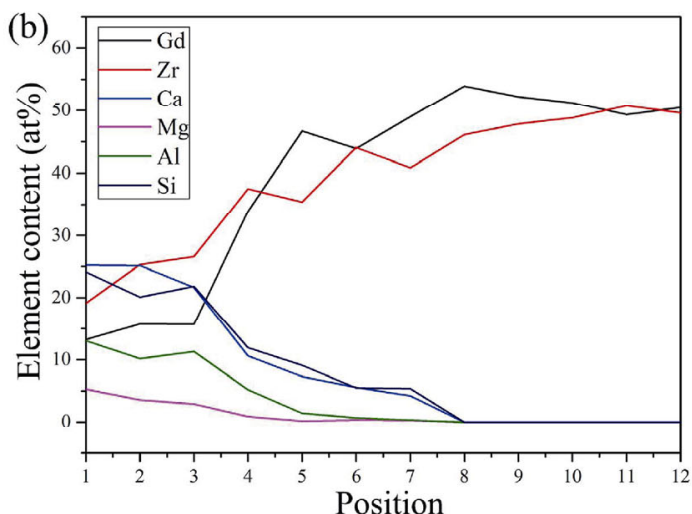

Fig. 9 (a) Cross-sectional morphology and (b) variation of each element along with the corrosion depth (GZ-1.0 after exposure to molten CMAS for $60 \mathrm{~min}$ ).

Penetration rates for all corroded coatings are evaluated by comparing the original coating and the remaining coating thickness via EDS element distribution analysis (Fig. 10). Meanwhile, the average penetration rate versus time for all deposited coatings is summarized in Table 2. The CMAS penetration rate of GZ-0.75 is much faster than others. The coating is completely infiltrated by molten CMAS in $30 \mathrm{~min}$. By analyzing the cross-section overview of GZ-0.75 after exposure to molten CMAS for 5 min (Fig. 11), the (a)
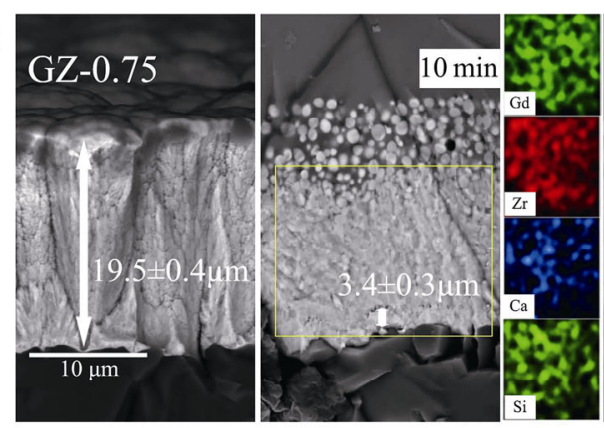

(b)
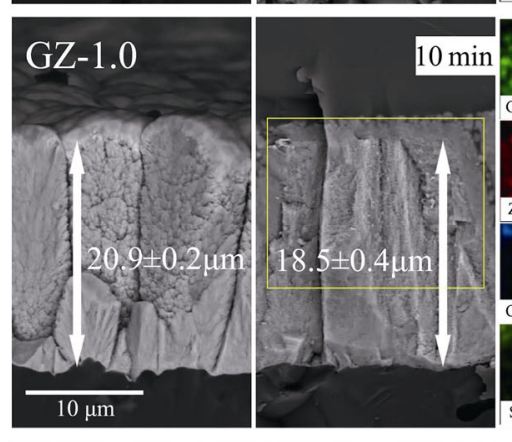

(c)
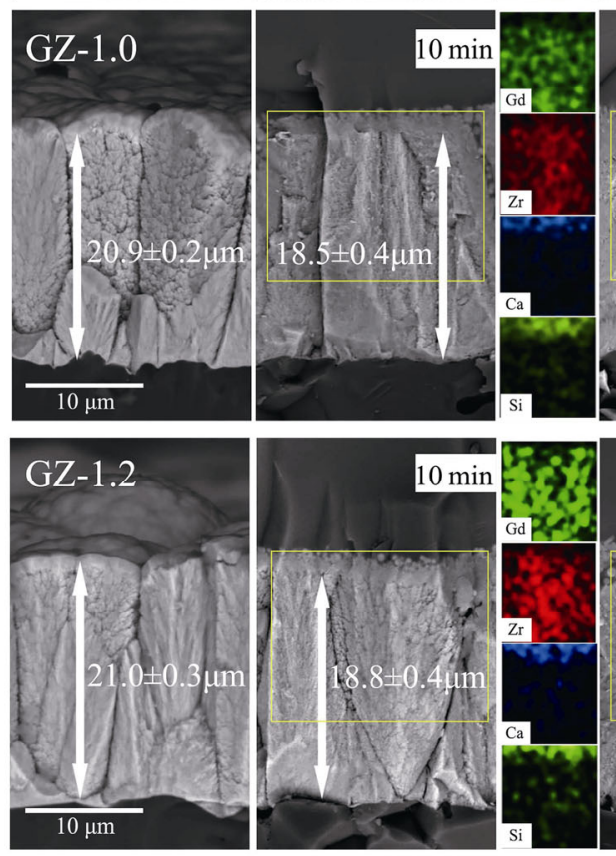
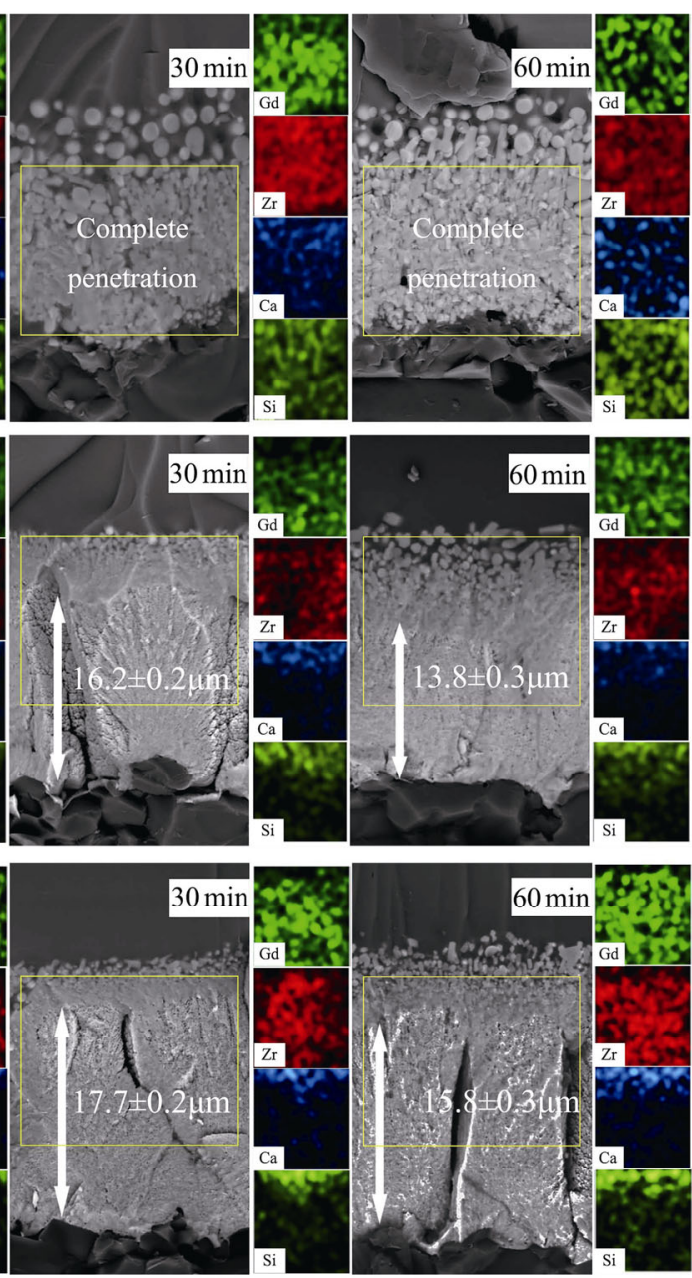

Fig. 10 Cross-sectional morphologies and element distributions of (a) GZ-0.75, (b) GZ-1.0, and (c) GZ-1.2 coatings after exposure to molten CMAS for 10, 30, and 60 min, respectively. 


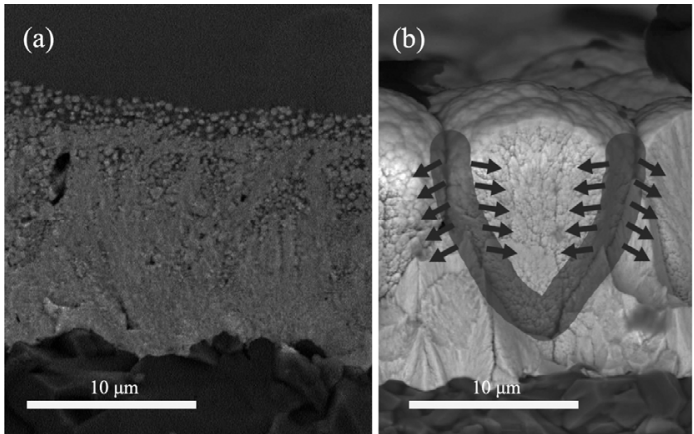

Fig. 11 (a) Cross-section mophology of GZ-0.75 after exposure to molten CMAS for $5 \mathrm{~min}$ and (b) the seepage path of molten CMAS along the gap between columnar strucures.

poor CMAS resistance is attributed to the insufficient amount of generated Gd-apatite to seal the intercolumnar gap. Such deep penetration greatly increases the contact area of molten CMAS and the coating, which accelerates the dissolution of GZ. As the Gd content increases, the clogging effect of apatite upon the CMAS penetration appears. For GZ-1.0, its coating thickness decreases from 19.5 to $18.5 \mu \mathrm{m}$ after $10 \mathrm{~min}$, to $16.2 \mu \mathrm{m}$ after $30 \mathrm{~min}$, and to $13.8 \mu \mathrm{m}$ after $60 \mathrm{~min}$, respectively. With the further increment of Gd content, the coating thickness of GZ-1.2 changes from 21.0 to 18.8, 17.7, and $15.8 \mu \mathrm{m}$ after exposure to molten CMAS for 10,30 , and $60 \mathrm{~min}$, respectively. Because of the clogging effect of Gd-apatite, the measured CMAS penetration rate of GZ-1.2 (GZ-1.0) drops from $13.2 \mu \mathrm{m} / \mathrm{h}$ $(14.4 \mu \mathrm{m} / \mathrm{h})$ for $10 \mathrm{~min}$ to $5.2 \mu \mathrm{m} / \mathrm{h}(7.1 \mu \mathrm{m} / \mathrm{h})$ for $60 \mathrm{~min}$, respectively. Here, the GZ-1.2 coating with the penetration rate of $5.2 \mu \mathrm{m} / \mathrm{h}$ is better than YSZ $(>100 \mu \mathrm{m}$, EB-PVD) and $\mathrm{La}_{2.5} \mathrm{Zr}_{1.5} \mathrm{O}_{6.75}(10.4 \mu \mathrm{m} / \mathrm{h}, \quad$ LCVD $)$ [42-44]. This result is also better than that $(7.5-15 \mu \mathrm{m} / \mathrm{h})$ of $\mathrm{Gd}_{2.0} \mathrm{Zr}_{2.0} \mathrm{O}_{7.0}$ coating fabricated by EB-PVD [34], which indicates that GZ-1.2 has an enhanced CMAS resistance.

The XRD peak at $\sim 28^{\circ}$ in Fig. 8 shifts to the left side gradually and finally splits into two peaks along with the rising of $\mathrm{Gd}$ content, which indicates the increment of generated Gd-apatite. To understand such a phenomenon, the main reaction between non-stoichiometric GZs and CMAS can be written as following chemical reaction (capital letters here represent the pure oxide phases, as $\mathrm{G}$ for $\mathrm{Gd}_{2} \mathrm{O}_{3}, \mathrm{Z}$ for $\mathrm{ZrO}_{2}$, C for $\mathrm{CaO}$, and $\mathrm{S}$ for $\mathrm{SiO}_{2}$ ) based on the EDS data in Table 3:

$\mathrm{G}_{0.5+x} \mathrm{Z}_{0.5-x}(\mathrm{GZ})+(0.22+0.34 x) \mathrm{C}+(0.44+0.89 x) \mathrm{S} \rightarrow$ $(1.14+2.27 x) \mathrm{C}_{0.17} \mathrm{G}_{0.44} \mathrm{~S}_{0.39}$ (apatite) $+(0.53-1.05 x)$ $\mathrm{C}_{0.05} \mathrm{Z}_{0.95}$ (zirconia)
Table 2 Penetration depth/rate comparison of all LCVD coatings

\begin{tabular}{cccc}
\hline \multirow{2}{*}{ Coating } & \multicolumn{3}{c}{ Penetration depth $(\mu \mathrm{m}) /$ rate $(\mu \mathrm{m} / \mathrm{h})$} \\
\cline { 2 - 4 } & $10 \mathrm{~min}$ & $30 \mathrm{~min}$ & $60 \mathrm{~min}$ \\
\hline GZ-0.75 & $16.1 / 96.6$ & \multicolumn{2}{c}{ Complete penetration } \\
GZ-1.0 & $2.4 / 14.4$ & $4.7 / 9.4$ & $7.1 / 7.1$ \\
GZ-1.2 & $2.2 / 13.2$ & $3.3 / 6.6$ & $5.2 / 5.2$ \\
\hline
\end{tabular}

Table 3 Average chemical compositions (at \%) in different positions of Figs. 7(b)-7(d) detected by EDS

\begin{tabular}{ccccc}
\hline Element & $\mathrm{Gd}$ & $\mathrm{Zr}$ & $\mathrm{Ca}$ & $\mathrm{Si}$ \\
\hline $\mathrm{A}$ & 43.89 & 0 & 15.82 & 40.29 \\
$\mathrm{~B}$ & 42.32 & 0 & 20.75 & 36.93 \\
$\mathrm{C}$ & 0 & 93.84 & 6.16 & 0 \\
$\mathrm{D}$ & 45.39 & 0 & 16.15 & 38.46 \\
$\mathrm{E}$ & 43.26 & 0 & 16.52 & 40.22 \\
$\mathrm{~F}$ & 0 & 92.76 & 7.24 & 0 \\
$\mathrm{G}$ & 45.39 & 0 & 16.15 & 38.46 \\
$\mathrm{H}$ & 43.26 & 0 & 16.52 & 40.22 \\
$\mathrm{I}$ & 0 & 98.21 & 1.79 & 0 \\
\hline
\end{tabular}

As anorthite is the by-product of CMAS degradation after consuming $\mathrm{Ca}$ and $\mathrm{Si}$, the existence of anorthite does not affect the corrosion behavior [41]. Thus, only zirconia and apatite are considered in Reaction (4). From Reaction (4), the effects of high Gd content on the coating's CMAS resistance can be concluded as follows: On one hand, it can be predicted that the amount of Gd-apatite produced in the GZ-1.2 case would be $10 \%$ (or $26 \%$ ) more than that in GZ-1.0 (or GZ-0.75) case, when each one molar of coatings is consumed. The generation of more apatite indicates that the micro-cracks inside the coating would be blocked quicker in the Gd excess case than that in the $\mathrm{Zr}$ excess case, and the higher consumption of CMAS would reduce the loss of the coating during the corrosion reaction; on the other hand, the amount of generated $\mathrm{ZrO}_{2}$ would be $10 \%$ (or $22 \%$ ) less than that in GZ-1.0 (or GZ-0.75). Namely, GZ-1.2 would be less affected by the huge volume variation of $\mathrm{ZrO}_{2}$ during thermal cycling. Thus, GZ with higher Gd content owns an advanced resistance against CMAS corrosion.

\section{Conclusions}

Three GZ coatings with different $\mathrm{Gd} / \mathrm{Zr}$ ratios are deposited onto $\mathrm{Al}_{2} \mathrm{O}_{3}$ substrate via $\mathrm{LCVD}$, and their CMAS corrosion resistance at $1250{ }^{\circ} \mathrm{C}$ is investigated. 
The result shows that the GZ-0.75 coating cannot generate enough Gd-apatite to restrict the CMAS penetration through the inter-columnar gap and exhibits a poor CMAS resistance. With the increment of Gd content, the effect of Gd-apatite on restricting CMAS penetration appears. The penetration rate of GZ-1.2 decreases to $5.2 \mu \mathrm{m} / \mathrm{h}$, which is $27 \%$ lower than that of GZ-1.0. Such a low penetration rate is attributed to the amount of generated Gd-apatite during the corrosion reaction. More apatite solid solution accelerates the formation of the sealing layer and restricts the CMAS penetration more efficiently. Meanwhile, a lower amount of $\mathrm{ZrO}_{2}$ generation would reduce the influence of the huge volume variation during thermal cycling. Thus, GZ-1.2 with higher Gd content has an improved CMAS resistance. This work uncovers the important role of the Gd element on the corrosion resistance of GZ coatings and is expected to guide the future development of GZ coatings with enhanced CMAS resistance.

\section{Acknowledgements}

This work was supported by the Natural Science Foundation of Shanghai (No. 20ZR1419200), National Natural Science Foundation of China (Nos. 52072232 and 52072231), and the Program for Professor of Special Appointment (Eastern Scholar) by Shanghai Municipal Education Commission (No. TP2015040).

\section{References}

[1] Levi CG, Hutchinson JW, Vidal-Setif MH, et al. Environmental degradation of thermal-barrier coatings by molten deposits. MRS Bull 2012, 37: 932-941.

[2] Clarke DR, Oechsner M, Padture NP. Thermal-barrier coatings for more efficient gas-turbine engines. MRS Bull 2012, 37: 891-898.

[3] Cao XQ, Vassen R, Stoever D. Ceramic materials for thermal barrier coatings. J Eur Ceram Soc 2004, 24: 1-10.

[4] Vassen R, Stuke A, Stöver D. Recent developments in the field of thermal barrier coatings. $J$ Therm Spray Technol 2009, 18: 181-186.

[5] Chen HF, Zhang C, Liu YC, et al. Recent progress in thermal/environmental barrier coatings and their corrosion resistance. Rare Met 2020, 39: 498-512.

[6] Craig M, Ndamka NL, Wellman RG, et al. CMAS degradation of EB-PVD TBCs: The effect of basicity. Surf Coat Technol 2015, 270: 145-153.

[7] Wellman R, Whitman G, Nicholls JR. CMAS corrosion of EB PVD TBCs: Identifying the minimum level to initiate damage. Int J Refract Met Hard Mater 2010, 28: 124-132.
[8] Liu B, Liu YC, Zhu CH, et al. Advances on strategies for searching for next generation thermal barrier coating materials. J Mater Sci Technol 2019, 35: 833-851.

[9] Chen L, Yang GJ. Epitaxial growth and cracking of highly tough 7YSZ splats by thermal spray technology. $J A d v$ Ceram 2018, 7: 17-29.

[10] Feng J, Xiao B, Zhou R, et al. Thermal conductivity of rare earth zirconate pyrochlore from first principles. Scripta Mater 2013, 68: 727-730.

[11] Yang L, Zhu CH, Sheng Y, et al. Investigation of mechanical and thermal properties of rare earth pyrochlore oxides by first-principles calculations. $J$ Am Ceram Soc 2019, 102: 2830-2840.

[12] Lehmann H, Pitzer D, Pracht G, et al. Thermal conductivity and thermal expansion coefficients of the lanthanum rareearth-element zirconate system. J Am Ceram Soc 2003, 86: $1338-1344$.

[13] Peng L, Zhang KB, He ZS, et al. Self-propagating high-temperature synthesis of $\mathrm{ZrO}_{2}$ incorporated $\mathrm{Gd}_{2} \mathrm{Ti}_{2} \mathrm{O}_{7}$ pyrochlore. $J A d v$ Ceram 2018, 7: 41-49.

[14] Michel D, Y Jorba MP, Collongues R. Study by Raman spectroscopy of order-disorder phenomena occurring in some binary oxides with fluorite-related structures. J Raman Spectrosc 1976, 5: 163-180.

[15] Li F, Zhou L, Liu JX, et al. High-entropy pyrochlores with low thermal conductivity for thermal barrier coating materials. J Adv Ceram 2019, 8: 576-582.

[16] Mao WG, Wang YJ, Shi J, et al. Bending fracture behavior of freestanding $\left(\mathrm{Gd}_{0.9} \mathrm{Yb}_{0.1}\right)_{2} \mathrm{Zr}_{2} \mathrm{O}_{7}$ coatings by using digital image correlation and FEM simulation with 3D geometrical reconstruction. $J A d v$ Ceram 2019, 8: 564-575.

[17] Liu B, Wang JY, Li FZ, et al. Theoretical elastic stiffness, structural stability and thermal conductivity of $\mathrm{La}_{2} \mathrm{~T}_{2} \mathrm{O}_{7}(\mathrm{~T}=$ Ge, Ti, Sn, Zr, Hf) pyrochlore. Acta Mater 2010, 58: 4369-4377.

[18] Liu B, Wang JY, Zhou YC, et al. Theoretical elastic stiffness, structure stability and thermal conductivity of $\mathrm{La}_{2} \mathrm{Zr}_{2} \mathrm{O}_{7}$ pyrochlore, Acta Mater 2007, 55: 2949-2957.

[19] Wu J, Wei XZ, Padture NP, et al. Low-thermal-conductivity rare-earth zirconates for potential thermal-barrier-coating applications. J Am Ceram Soc 2002, 85: 3031-3035.

[20] Padture NP. Thermal barrier coatings for gas-turbine engine applications. Science 2002, 296: 280-284.

[21] Krämer S, Yang J, Levi CG. Infiltration-inhibiting reaction of gadolinium zirconate thermal barrier coatings with CMAS melts. J Am Ceram Soc 2008, 91: 576-583.

[22] Krämer S, Yang J, Levi CG, et al. Thermochemical interaction of thermal barrier coatings with molten $\mathrm{CaO}-$ $\mathrm{MgO}-\mathrm{Al}_{2} \mathrm{O}_{3}-\mathrm{SiO}_{2}$ (CMAS) deposits. J Am Ceram Soc 2006, 89: 3167-3175.

[23] Stanek CR, Minervini L, Grimes RW. Nonstoichiometry in $\mathrm{A}_{2} \mathrm{~B}_{2} \mathrm{O}_{7}$ pyrochlores. J Am Ceram Soc 2002, 85: 2792-2798.

[24] Wuensch BJ, Eberman KW. Order-disorder phenomena in $\mathrm{A}_{2} \mathrm{~B}_{2} \mathrm{O}_{7}$ pyrochlore oxides. JOM 2000, 52: 19-21.

[25] Scheetz BE, White WB. Characterization of anion disorder in zirconate $\mathrm{A}_{2} \mathrm{~B}_{2} \mathrm{O}_{7}$ compounds by Raman spectroscopy. $J$ 
Am Ceram Soc 1979, 62: 468-470.

[26] Cao XQ, Vassen R, Jungen W, et al. Thermal stability of lanthanum zirconate plasma-sprayed coating. $J$ Am Ceram Soc 2001, 84: 2086-2090.

[27] Pannetier J. Energie electrostatique des reseaux pyrochlore. J Phys Chem Solids 1973, 34: 583-589.

[28] Mauer G, Schlegel N, Guignard A, et al. Plasma spraying of ceramics with particular difficulties in processing. $J$ Therm Spray Technol 2015, 24: 30-37.

[29] Mauer G, Sebold D, Vaßen R, et al. Improving atmospheric plasma spraying of zirconate thermal barrier coatings based on particle diagnostics. J Therm Spray Technol 2012, 21: 363-371.

[30] Schmitt MP, Stokes JL, Gorin BL, et al. Effect of Gd content on mechanical properties and erosion durability of sub-stoichiometric $\mathrm{Gd}_{2} \mathrm{Zr}_{2} \mathrm{O}_{7}$. Surf Coat Technol 2017, 313: 177-183.

[31] Duty C, Jean D, Lackey WJ. Laser chemical vapour deposition: Materials, modelling, and process control. Int Mater Rev 2001, 46: 271-287.

[32] Goto T, Kimura T. High-speed oxide coating by laser chemical vapor deposition and their nano-structure. Thin Solid Films 2006, 515: 46-52.

[33] Yang G, Wang DJ, Zhang C, et al. Fabrication of gadolinium zirconate films by laser CVD. Ceram Int 2019, 45: 49264933.

[34] Wang L, Guo L, Li ZM, et al. Protectiveness of Pt and $\mathrm{Gd}_{2} \mathrm{Zr}_{2} \mathrm{O}_{7}$ layers on EB-PVD YSZ thermal barrier coatings against calcium-magnesium-alumina-silicate (CMAS) attack. Ceram Int 2015, 41: 11662-11669.

[35] Cai Y, Coyle TW, Azimi G, et al. Superhydrophobic ceramic coatings by solution precursor plasma spray. Sci Rep 2016, 6: 24670.

[36] Algenaid W, Ganvir A, Calinas RF, et al. Influence of microstructure on the erosion behaviour of suspension plasma sprayed thermal barrier coatings. Surf Coat Technol 2019, 375: 86-99.

[37] Zhou FF, Xu LP, Deng CM, et al. Nanomechanical characterization of nanostructured $\mathrm{La}_{2}\left(\mathrm{Zr}_{0.75} \mathrm{Ce}_{0.25}\right)_{2} \mathrm{O}_{7}$ thermal barrier coatings by nanoindentation. Appl Surf Sci
2020, 505: 144585.

[38] Guo L, Zhang Y, Ye FX. Phase structure evolution and thermo-physical properties of nonstoichiometry $\mathrm{Nd}_{2-x} \mathrm{Zr}_{2+x} \mathrm{O}_{7+x / 2}$ pyrochlore ceramics. J Am Ceram Soc 2015, 98: 1013-1018.

[39] Zhao JL, Liu YC, Fan Y, et al. Native point defects and oxygen migration of rare earth zirconate and stannate pyrochlores. J Mater Sci Technol 2021, 73: 23-30.

[40] Subramanian MA, Aravamudan G, Subba Rao GV. Oxide pyrochlores-A review. Prog Solid State Chem 1983, 15: 55-143.

[41] Mechnich P, Braue W. Volcanic ash-induced decomposition of EB-PVD $\mathrm{Gd}_{2} \mathrm{Zr}_{2} \mathrm{O}_{7}$ thermal barrier coatings to Gd-oxyapatite, zircon, and Gd, Fe-zirconolite. J Am Ceram Soc 2013, 96: 1958-1965.

[42] Zhang CG, Zhao JL, Yang L, et al. Preparation and corrosion resistance of nonstoichiometric lanthanum zirconate coatings. J Eur Ceram Soc 2020, 40: 3122-3128.

[43] Drexler JM, Gledhill AD, Shinoda K, et al. Jet engine coatings for resisting volcanic ash damage. Adv Mater 2011, 23: 2419-2424.

[44] Zhu CH, Liu YC, Wang DJ, et al. Improved resistance of lanthanum zirconate coatings to calcium-magnesiumalumina-silicate corrosion through composition tailoring. Ceram Int 2018, 44: 13908-13915.

Open Access This article is licensed under a Creative Commons Attribution 4.0 International License, which permits use, sharing, adaptation, distribution and reproduction in any medium or format, as long as you give appropriate credit to the original author(s) and the source, provide a link to the Creative Commons licence, and indicate if changes were made.

The images or other third party material in this article are included in the article's Creative Commons licence, unless indicated otherwise in a credit line to the material. If material is not included in the article's Creative Commons licence and your intended use is not permitted by statutory regulation or exceeds the permitted use, you will need to obtain permission directly from the copyright holder.

To view a copy of this licence, visit http://creativecommons. org/licenses/by/4.0/. 